\title{
CHOROIDAL DETACHMENT FOLLOWING OPERATION FOR DETACHED RETINA*
}

\author{
BY \\ J. GIBSON MOORE \\ London
}

THE incidence of choroidal detachment following operation for detached retina is not easy to assess and reports in the literature are very scanty. It probably occurs quite often where free drainage of the sub-retinal fluid is made and the eye is in a state of hypotension, but passes unnoticed unless an examination is made immediately.

\section{Case Report}

A married female aged 51 noticed flickering spots in front of the right eye, succeeded by a shadow in the lower and outer field of vision.

She was first examined on March 21, 1953, 5 weeks after the onset and a shallow retinal detachment was noted in the upper nasal quadrant. She was emmetropic with $6 / 6$ vision in each eye. Repeated examination revealed no hole and a period of rest in bed did not influence the appearance.

At operation the area of the detachment was covered with diathermy punctures spaced at intervals of about $3 \mathrm{~mm}$. extending back $14 \mathrm{~mm}$. in the shape of a semi-circle from the ora serrata. There was quite free drainage of sub-retinal fluid and the retina appeared flat. Air was not injected into the vitreous and the eye was soft at the end of the operation.

The convalescence was uneventful, but, when detailed examination was made 7 days later, two small choroidal detachments were noted, one in the supernasal quadrant and the other in the supertemporal quadrant, separated by a definite interval. It was not. likely that these were due to actual hæmorrhage at the time of operation as the supernasal one was not over the site of the detachment:

The anterior chamber remained of normal depth the whole time and it was not until 8 weeks after that the retina was seen to be in position where it has remained ever since.

\section{Discussion}

The unusual nature of this occurrence leads one to consider how it could develop. In the many papers dealing with choroidal detachment following glaucoma and cataract operations the most commonly quoted theories are:

(1) Formation of a cyst in the retina (Haab, 1891).

(2) Cyst-like detachment in the epithelium of the ciliary body (Velhagen, 1897).

(3) Serous exudate from the choroidal blood-vessels under conditions of abnormally low tension (Hudson, 1914; O'Brien, 1935).

(4) Formation of a rent in the angle of the anterior chamber and the seepage of fluid into the perichoroidal space (Fuchs, 1900; Rycroft, 1943).

Taking the last theory first, it is attractive to have a definite pathology, i.e., a rent which can be visualized, but there are several objections:

(a) If a rent is present the aqueous must now pass in two directions, both through the external wound made at the limbus (in glaucoma and cataract operations) and also backwards into the perichoroidal space, and this is difficult to understand.

(b) The rent must be made at the moment when the anterior chamber is lost at

*Received for publication March 1, 1954. 
operation. When a very hard eye is opened it is very noticeable that no tremendous mechanical stresses of an explosive nature are set up, such as one might expect and would be required by this pathology. Instead the aqueous flows out quite quietly while the anterior chamber is lost.

(c) Only one case of choroidal detachment has been noted after cyclodialysis (Heine, 1905) in many hundreds of cases. Rycroft (1943) has considered the rent theory favourably and in detail but with an open mind records this objection.

No-one has ever seen this rent and its existence is hypothetical. This does not, of course, exclude its possibility, but it is necessary in any valid hypothesis for the physical facts to accord with the theory. If one tries to visualize what happens when the anterior chamber is lost during a glaucoma or cataract operation it is true that the lens moves anteriorly and with it the iris. The iris is by no means a flimsy membrane and it is well accustomed to variations in position. It would require to be in strong miosis and firmly fixed at the pupillary margin for there to be any strain such as might produce a rent at its root. It is unfortunate that it is, of course, impossible to examine the angle when the anterior chamber is absent as this would clinch the matter, and even when no rent is found when the chamber is examined gonioscopically after reformation it is possible that it is then not visible through the anterior synechia which commonly form peripherally after operation.

The third theory merely requires a condition of prolonged hypotension; the choroidal detachment being produced by serous exudate from the choroidal vessels and it is the only reasonable theory that could explain its occurrence after operation for retinal detachment. O'Brien (1935) states that the fluid aspirated is derived from blood and not from aqueous, and this, of course, is very definite evidence that the fluid is derived from the choroidal veins. Duke-Elder (1940) writes:

Owing to the sudden lowering of the intra-ocular pressure and the abolition of the anterior chamber allowing the lens and vitreous to move forwards, there is a transudation of fluid from the choroidal veins into the perichoroidal space.

This is the most likely explanation of the mechanism of choroidal detachment, but I feel that the forward movement of the lens and vitreous is not essential although it occurs in the great majority of cases because the external wound is in front of the plane of the iris. If, however, the external wound is behind the iris as in the case here described, the anterior chamber would not be lost and might even become deeper. All that is required is a condition to be set up in which the intra-ocular fluid is being lost externally at a higher rate than it can be produced by its normal sites of origin.

\section{Summary}

A case of choroidal detachment following operation for retinal detachment is reported. It is considered that this occurrence tends to disprove the rent theory in the formation of choroidal detachment.

REFERENCES

DUKE-ELDER, S. (1940). “" Text-book of Ophthalmology ”, vol. 3, p. 2540. Kimpton, London.

FUCHS, E. (1900). v. Graefes Arch. Ophthal., 51, 199.
HAAB, O. (1891). Beitr. Augenheilk., 1, heft 2, p. 23.

HEINE, L. (1905). Ber. ophthal. Ges. Heidelberg, $32,3$.

Hudson, A. C. (1914). Roy. Lond. ophthal. Hosp. Rep., 19, 301.

O'Brien, C. S. (1935). Arch. Ophthal. (Chicago), 14, 527.

RYCROFT, B. W. (1943). British Journal of Ophthalmology, 27, 283.

VELHAGEN (1897). Zbl. prakt. Augenheilk., 21, 363. 